years old. Twenty tree protectors were placed about the trees in mid June, and resealed, as in the first plot. At the close of the season they were examined for borers. The per cent of infestation was 30 , as compared to 40 per cent in the check plot. In this second plot a number of large ant nests were found under the protectors, which served as ideal places under which to build their nests.

Perhaps the failure of the tree protectors in this case may be explained by the fact that the high winds sweeping over Lake Erie and Sandusky Bay sway the trees to such an extent that it is very difficult to keep the protectors tightly sealed for any length of time.

President R. A. Cooley: Is there any further discussion on this paper? If not, I will call for the next paper, "The Apple Ermine Moth in New York," by Mr. Parrott, of Geneva, N. Y.

This paper will be presented by Mr. Fulton.

\title{
THE APPLE ERMINE MOTH
}

\section{By P. J. Parrotr, New York Agricultural Experiment Station}

In the Journal of Economic Entomology, vol. 3, p. 157, a brief account was given of the occurrence of the cherry ermine moth ( $Y$ ponomeuta padellus L.) on imported cherry seedlings. Since the publication of this article an associated species has been observed on apple, and it is desired at this time to place on record some notes relative to its identity and distribution in nurseries and orchards.

Of the various species of insects imported from Europe on apple seedlings no other is more persistent or occurs in such large numbers as the ermine moth. Since our attention was attracted to it in 1910, no year has passed that the horticultural inspectors have not discovered colonies of caterpillars in plantings of foreign stocks. Moreover, recent years have witnessed greatly increased numbers of the insects. During 1915 and 1916 approximately 4,223 infested plants were discovered, while during 1917 all previous records were exceeded as 13,674 seedlings infested with caterpillars were discovered and destroyed. In view of the experiences in New York it is a significant fact that neither this species nor the associated form have so far been reported from any other state. The only area on the American continent outside of the state of New York from which the insect has been reported is New Brunswick where, according to Dr. Hewitt, it was found necessary to destroy 450 imported apple seedlings because of the presence of egg masses.

Aside from the increased abundance of the insects in foreign importations, we have also to record the discovery of the pest in three bear- 
ing orchards in the region of Seneca Castle, by Messrs. Maney and Rupert, Horticultural Inspectors of the State Department of Agriculture. The orchards were in the immediate vicinity of nursery plantations, and the infestation of the trees unquestionably occurred during 1916, when moths originating from eggs on imported apple seedlings sought neighboring orchards for purposes of oviposition. Notwithstanding the presence of other kinds of fruit, the infestation was entirely confined to apple trees.

The occurrence of the insect on apple and not on cherry raises the question to which species it belongs,- - to padellus or malinellus? As we have previously pointed out, the moths of the former species are exceedingly variable in their markings, and unfortunately the identification of the two species seems to rest largely upon color distinction of the adult insects. In spite of seeming morphological and biologic differences, the separation of these insects is difficult and unsatisfactory; and there exists consequently considerable uncertainty as to the actual status of these two forms. The adults of padellus reared from cherry and hawthorn particularly, and of malinellus from apple represent for the most part extremes in wing coloration. The former contains a majority of moths which have the primaries and fringes clouded, greyish or lead colored, while the latter has a majority of moths with primaries and fringes white. The two are distinct enough when characteristic examples are selected, but the separation of them becomes difficult when the intergrading forms are considered, as they merge into each other by imperceptible gradations.

In order that the moths recently bred from apples should be correctly identified, specimens were forwarded to Dr. Paul Marchal, Paris, who has devoted considerable attention to these insects, and in a letter dated October 20,1917, he reports as follows: "The Hyponomeutas which you forwarded to me have arrived. They were in rather bad condition as the wings of two specimens were detached; however they agree well with the species $H$. malinellus. They are distinguishable from padellus by the front wings, the ground color of which is white, while the margins, examined from below, are finely bordered with white. The fringe of the anterior wings is also mostly white, and not grey as with padellus. Although the moths are considered distinct species I am not at all certain but that under certain conditions one form may produce the other. It cannot be positively denied that they are not two varieties of the same species."

Breeding experiments are needed to definitely settle the status of the two moths, but until these are undertaken the example of European writers may well be followed of designating the insects bred on hawthorn and cherry as padellus and those from apple as malinellus. 